\title{
ANALISIS FAKTOR-FAKTOR YANG MENDORONG WISATAWAN MELAKUKAN KEPUTUSAN PEMBELIAN TIKET PESAWAT MELALUI MOBILE BOOKING PADA SITUS TRAVELOKA.COM
}

\author{
Erni Muliana \\ I Made Kusuma Negara \\ Luh Gede Leli Kusuma Dewi \\ Email : ernimuliana@gmail.com \\ PS. S1 Industri Perjalanan Wisata \\ Fakultas Pariwisata UNUD
}

\begin{abstract}
ABSTRAK
Pembelian kebutuhan perjalanan wisata secara online merupakan bagian dari transaksi business to-customer (B2C). Produk yang ditawarkan biasanya terdiri dari: pemesanan paket wisata, penjualan tiket pesawat dan kereta api, kamar hotel dan penyewaan transportasi. Penelitian dilakukan dengan tujuan untuk mengetahui faktor-faktor yang mendorong wisatawan melakukan keputusan pembelian tiket pesawat melalui mobile booking pada situs Traveloka.com serta faktor yang paling banyak berkontribusi dalam menentukan keputusan pembelian tersebut. Teknik pengumpulan data yang digunakan adalah kuesioner online dan kuesioner yang disebarkan secara langsung (offline) kepada 250 responden, penentuan responden ditetapaka menggunakn metode purposive sampling, sedangkan teknik analisis data yang digunakan adalah teknik analisis faktor. Hasil analisis faktor yang didapatakan menjelaskan $67,066 \%$ dari keseluruhan total variance, dan hasil analisis data menunjukkan empat faktor terbentuk yang mendorong wisatawan melakukan keputusan pembelian tiket pesawat melalui mobile booking pada situs Traveloka.com, yaitu: kemudahan dan sistem informasi website $(24,396 \%)$, pelayanan konsumen/customer service $(15,211 \%)$, citra perusahaan $(14,681 \%)$, dan motivasi pembelian $(12,779 \%)$, adapun faktor yang paling berkontribusi dalam mendorong wisatawan melakukan keputusan pembelian tiket pesawat melalui mobile booking pada situs Traveloka.com adalah faktor terbentuk yang memiliki faktor laoding tertinggi dari keseluruhan faktor yang terbentuk, yaitu faktor "Kemudahan dan Sistem Informasi Website", faktor ini terdiri dari 13 variabel yakni: (1) Kemudahan pencarian situs web, (2) kecepatan waktu mengakses (load time), (3) nama domain perusahaan, (4) kemudahan pemesanan, (5) Informasi yang lengkap, (6) Informasi yang akurat, (7) Informasi yang menarik, (8) Pemaparan informasi yang tepat, (9) Ketersediaan dan aksesibilitas, (10) Harga yang kompetitif, (11) Pengalaman secara keseluruhan, (12) Keamanan data pribadi, dan (13) Keamanan sistem pembayaran.
\end{abstract}




\section{LATAR BELAKANG}

Perkembangan teknologi informasi kini telah masuk dalam era digital dimana segala bentuk informasi dapat diakses dengan begitu cepat dan mudah melalui perangkat teknologi. Pemanfaatan teknologi dan informasi menyebabkan kebiasaan baru dalam segala aspek kehidupan. Dalam dunia bisnis, penerapan teknologi informasi sudah diterapkan oleh perusahaan yang berskala nasional maupun internasional, salah satunya sistem $e$ bussines. Seiring dengan perkembangan tersebut para pelaku bisnis berlomba lomba memasarkan produk dan jasa yang dimiliki melalui situs internet dengan harapan agar informasi tentang produk yang dimiliki lebih cepat menyebar luas ke seluruh lapisan masyarakat. Pergeseran kebiasaan (trend) berbelanja melalui internet berkembang begitu pesat.

Proses pencarian informasi serta sistem belanja online yang mudah menjadikan trend berbelanja online di Indonesia begitu diminati. Seorang konsumen juga dapat membandingkan harga dari beberapa situs online sebelum melakukan keputusan pembelian. Belanja online bukan hanya pada kebutuhan pokok atau produk seperti baju, makanan, property dan alat elektronik melainkan sudah merambah ke semua jenis kebutuhan jasa dan produk lainnya. Salah satu jenis jasa yang banyak ditawarkan di situs online adalah segala bentuk kebutuhan perjalanan untuk para wisatawan, misalnya: pemesanan paket wisata, tiket pesawat, tiket kereta api, voucher hotel dan lain sebagainya. Adanya pergeseran dari mass tourism menjadi individual tourism menyebabkan kebiasaan baru yakni wisatawan melakukan pemesanan kamar hotel, tiket pesawat, transportasi dan segala kebutuhan dalam melakukan perjalanan wisata lainya secara mandiri. Tiket pesawat merupakan salah satu kebutuhan wisatawan yang akan berlibur ke suatu daerah tujuan wisata yang biasanya tidak dapat atau lebih sulit di akses melalui darat dan laut. Situs online booking tiket pesawat memberikan kemudahan bagi para wisatawan untuk dapat mengakses dan memantau harga tiket dimanapun dan kapanpun tanpa harus datang langsung ke kantor penjualan tiket.

PT. Traveloka.com Indonesia yang lebih di kenal dengan Traveloka.com merupakan salah satu situs online travel agent yang menyediakan jasa penjualan tiket pesawat dan hotel voucher. sejak diresmikan pada tahun 2012 situs Traveloka.com mendapat berbagai pengharagaan seperti: Indonesia's No. 1 Flight and Hotel Booking Service according to comScore, Garuda Indonesia's best performing GOS Agent 2014, Sriwijaya Air Best Travel Agent 2013 \& 2014 dan Citilink Best Travel Agent 2013. selain itu pada tanggal 31 Juli 2014 Traveloka.com situs layanan jasa perjalanan online ini merilis aplikasi mobile untuk para penggunanya di Indonesia dan mendapat respon yang bagus dari masyarakat. Hal ini sesuai dengan popularitas perangkat mobile di Indonesia yang semakin tinggi. Dimana banyak pengguna internet lebih memilh online dari posel atau tablet jika dibandingkan dengan menggunakan perangkat komputer.

\section{METODE}

Variabel yang digunakan berbentuk variabel bebas (independent variables) yakni dengan cara mengadopsi beberapa konsep dari buku dan hasil penelitian sebelumnya terkait faktor apa saja yang mempengaruhi keputusan pembelian konsumen pada saat berbelanja secara online, yang dijadikan sebagai konsep awal untuk mengetahui faktor-faktor yang mendorong wisatawan melakukan keputusan pembelian tiket pesawat melalaui mobile booking pada situs Traveloka.com. Terdapat delapan faktor awal dengan 25 varibel yang digunakan, yaitu: Kemudahan pada saat mencari situs web $\left(\mathrm{X}_{1}\right)$, waktu yang dihabiskan untuk mngakses $\left(\mathrm{X}_{2}\right)$, nama domain perusahaan yang digunakan $\left(\mathrm{X}_{3}\right)$, kemudahan pada saat melakukan pemesanan $\left(\mathrm{X}_{4}\right)$, informasi yang lengkap $\left(\mathrm{X}_{5}\right)$, informasi yang akurat $\left(\mathrm{X}_{6}\right)$, informasi yang disajiakan menarik $\left(\mathrm{X}_{7}\right)$,tampilan warna web yang menarik $\left(\mathrm{X}_{8}\right)$, jenis huruf mudah di mengerti $\left(\mathrm{X}_{9}\right)$, pemaparan informasi yang tepat $\left(\mathrm{X}_{10}\right)$, kemudahan pengaduan keluhan $\left(\mathrm{X}_{11}\right)$, kecepatan waktu pelayanan $\left(\mathrm{X}_{12}\right)$, ketepatan waktu pelayanan $\left(\mathrm{X}_{13}\right)$, ketersediaan dan aksesibilitas $\left(\mathrm{X}_{14}\right)$, harga yang kompetetif $\left(\mathrm{X}_{15}\right)$, pengalaman secara $\left(\mathrm{X}_{16}\right)$, keamanan data pribadi $\left(\mathrm{X}_{17}\right)$, keamanan pada saat melakukan pembayaran $\left(\mathrm{X}_{18}\right)$, dorongan keluarga $\left(\mathrm{X}_{19}\right)$, situasi konsumen $\left(\mathrm{X}_{20}\right)$, personal image $\left(\mathrm{X}_{21}\right)$, Nama baik $\left(\mathrm{X}_{22}\right)$, reputasi dibanding pesaing $\left(\mathrm{X}_{23}\right)$, dikenal luas $\left(\mathrm{X}_{24}\right)$, kemudahan diingat $\left(\mathrm{X}_{25}\right)$. 


\section{Sumber data dan teknik pengumpulan data}

Sumber data dibagi menjadi dua, yaitu data primer berbentuk kuesioner yang disebarakan kepada responden dan data sekunder adalah data pendukung lainya. Metode pengumpulan data yang digunakan adalah kuesioner, dokumentasi dan survei online.

\section{Teknik Penentuan Populasi dan Sampel}

Populasi yang digunakan sebagai sampel ditetapkan menggunakan teknik purposive sampling, sehingga semua sampel terdiri dari wisatawan yang pernah melakukan pembelian tiket pesawat melalui mobile booking pada situs Traveloka.com, adapaun penentuan jumlah sampel minimal 5 x 25=125 sampel, sedangkan maksimalnya berjumlah 10 x $25=250$ sampel (Ferdinan, 2006).

\section{Teknik Analisis Data}

Teknik analisis data yang digunakan adalah uji validitas dan reliabilitas instrumen dan dilanjutkan dengan analisis faktor.

\section{HASIL}

\section{Karakteristik Responden}

Hasil dari data kuesionar yang disebarakan kepada 250 wisawatawan didominasi oleh jenis kelamin perempuan sejumlah 139 wisatawan, dengan rentang usia 20-30 tahun, 162 wisatawan dengan pekerjaan pelajar/mahasiswa, rata-rata tingkat pendidikan terakhir didominasi oleh SLTA sejumlah 117 wisatawan. Pengeluaran rata-rata responden yang paling mendominasi berkisar Rp. 1.000.000-2.000.000/bulan.

\section{Uji Validitas dan Reliabilitas}

Nilai koefisien korelasi masingmasing variabel $>0,367$ itu berati semua instrumen-instrumen variabel dinyatakan valid.

Tabel 1: Hasil Uji Reliabilitas

\begin{tabular}{|l|l|l|r|}
\hline \multicolumn{3}{|c|}{ Reliability Statistics } \\
\hline $\begin{array}{l}\text { Cronbach's } \\
\text { Alpha }\end{array}$ & Part 1 & Value & .952 \\
\cline { 2 - 4 } & N of Items & $13^{\mathrm{a}}$ \\
\cline { 2 - 4 } & Part 2 & Value & .925 \\
\cline { 2 - 3 } & N of Items & $12^{\mathrm{b}}$ \\
\cline { 2 - 3 } & \multicolumn{2}{|c|}{ Total N of Items } & 25 \\
\hline Correlation Between Forms & .857 \\
\hline $\begin{array}{l}\text { Spearman- } \\
\text { Brown } \\
\text { Coefficient }\end{array}$ & \multicolumn{2}{|l|}{ Equal Length } & .923 \\
\cline { 2 - 3 } & Unequal Length & .923 \\
\hline
\end{tabular}

\begin{tabular}{|l|r|}
\hline Guttman Split-Half Coefficient & .922 \\
\hline
\end{tabular}

Sumber: Hasil olahan peneliti, 2015

Tabel diatas menunjukkan bahwa nilai korelasi Guttman Split-Half Coefficient $=0,922$. Korelasi berada pada kategori sangat kuat, bila dibandingkan dengan $r_{\text {tabel }}(0,367)$ maka $r_{\text {hitung }}$ lebih besar dari $r_{\text {tabel, }}$ dengan demikian bisa disimpulkan bahwa angket tersebut reliabel.

\section{Analisis faktor}

Analisis faktor merupakan independent technique yaitu teknik analisis multivariate untuk melacak (exploratory) hubungan dari seluruh independent variable (butir item) dengan variabel lainnya.

1. Penentuan dan Uji Kelayakan Variabel Terdapat delapan faktor awal yang terdiri dari 25 variabel, semua data variabel yang diolah dengan analisis faktor akan menghasilkan matrik korelasi. Hasil matrik korelasi digunakan untuk mengidentifikasi variabelvariabel yang saling berhubungan, variabelvariabel yang tidak saling berhubungan dengan variabel lain dikeluarkan dari analisis, untuk menguji bahwa 25 variabel saling berhubungan diperlihatkan oleh nilai KMO (Kaiser-Meyer-Olkin) harus lebih besar atau sama dengan 0,5 nilai besaran Bartlett's Test of Sphericity pada signifikan $<0,05$ menunjukkan hubungan antara variabelvariabel tersebut signifikan. Uji Measure of Sampling Adequency (MSA) dengan kriteria MSA $\geq 0,5$ menunjukkan derajat korelasi antar variabel yang erat.

Tabel 2: Hasil Uji KMO dan Bartlett's Test

\begin{tabular}{|l|l|r|}
\hline \multicolumn{3}{|c|}{ KMO and Bartlett's Test } \\
\hline $\begin{array}{l}\text { Kaiser-Meyer-Olkin Measure } \\
\text { of Sampling Adequacy. }\end{array}$ & .934 \\
\hline $\begin{array}{l}\text { Bartlett's Test of } \\
\text { Sphericity }\end{array}$ & $\begin{array}{l}\text { Approx. } \\
\text { Chi-Square }\end{array}$ & 4365.547 \\
\cline { 2 - 3 } & df & 300 \\
\cline { 2 - 3 } & Sig. & .000 \\
\hline
\end{tabular}

Sumber: Hasil olahan peneliti, 2015

Dapat dijelaskan bahwa besarnya KaiserMeyer-Olkin $(\mathrm{KMO})=0,934$ menunjukkan bahwa nilai KMO di atas 0,50. Hasil Bartlett's Test of Sphericity $=4365,547$ pada signifikan $=0,000$. Hasil ini menunjukkan bahwa antar variabel terjadi korelasi (signifikan $<0,05$ ), sehingga model faktor dapat digunakan.

Tabel 3: Hasil Uji MSA 


\begin{tabular}{|c|c|}
\hline Variabel & MSA \\
\hline Kemudahan mencari situs web $\left(\mathrm{X}_{1}\right)$ & 0,947 \\
\hline $\begin{array}{l}\text { Waktu yang dihabiskan untuk } \\
\text { mengakses web }\left(\mathrm{X}_{2}\right)\end{array}$ & 0,949 \\
\hline $\begin{array}{l}\text { Nama domain perusahaan yang } \\
\text { digunakan }\left(\mathrm{X}_{3}\right)\end{array}$ & 0,970 \\
\hline $\begin{array}{l}\text { Kemudahan pada saat pemesanan } \\
\left(\mathrm{X}_{4}\right)\end{array}$ & 0,962 \\
\hline Informasi yang lengkap $\left(\mathrm{X}_{5}\right)$ & 0,955 \\
\hline Informasi yang akurat $\left(\mathrm{X}_{6}\right)$ & 0,953 \\
\hline $\begin{array}{l}\text { Informasi yang disajikan menarik } \\
\left(\mathrm{X}_{7}\right)\end{array}$ & 0,972 \\
\hline Tampilan warna website $\left(\mathrm{X}_{8}\right)$ & 0,889 \\
\hline $\begin{array}{l}\text { Tampilan jenis huruf pada website } \\
\left(\mathrm{X}_{9}\right)\end{array}$ & 0,893 \\
\hline $\begin{array}{l}\text { Pemaparan informasi yang tepat } \\
\left(\mathrm{X}_{10}\right)\end{array}$ & 0,967 \\
\hline $\begin{array}{l}\text { Kemudahan pengaduan Keluhan } \\
\left(\mathrm{X}_{11}\right)\end{array}$ & 0,915 \\
\hline Kecepatan waktu pelayanan $\left(\mathrm{X}_{12}\right)$ & 0,876 \\
\hline Ketepatan waktu pelayanan $\left(\mathrm{X}_{13}\right)$ & 0,892 \\
\hline ketersediaan dan aksesibilitas $\left(\mathrm{X}_{14}\right)$ & 0,959 \\
\hline Harga yang kompetetif $\left(\mathrm{X}_{15}\right)$ & 0,922 \\
\hline $\begin{array}{lll}\begin{array}{l}\text { Pengalaman } \\
\left(\mathrm{X}_{16}\right)\end{array} & & \\
\end{array}$ & 0,929 \\
\hline Kamanan data pribadi $\left(\mathrm{X}_{17}\right)$ & 0,962 \\
\hline Keamanan sistem pembayaran $\left(\mathrm{X}_{18}\right)$ & 0,956 \\
\hline $\begin{array}{l}\text { Dorongan keluarga } \quad \text { (family } \\
\text { members })\left(\mathrm{X}_{19}\right)\end{array}$ & 0,916 \\
\hline Situasi konsumen $\left(\mathrm{X}_{20}\right)$ & 0,884 \\
\hline Personal image $\left(\mathrm{X}_{21}\right)$ & 0,818 \\
\hline Nama baik Perusahaan $\left(X_{22}\right)$ & 0,911 \\
\hline Reputasi dibanding pesaing $\left(\mathrm{X}_{23}\right)$ & 0,942 \\
\hline Dikenal luas $\left(\mathrm{X}_{24}\right)$ & 0,904 \\
\hline Kemudahan diingat $\left(\mathrm{X}_{25}\right)$ & 0,937 \\
\hline
\end{tabular}

Sumber: Hasil olahan peneliti, 2015

Hasil Measure of Sampling Adequency (MSA) dari 25 variabel yang diamati dalam model telah memenuhi kriteria $\mathrm{MSA} \geq 0,5$ yang menunjukkan bahwa hubungan antar variabel sangat erat.

2. Proses Faktoring, Rotasi dan Interpretasi faktor

Proses inti dari analisis faktor adalah melakukan ekstraksi dan rotasi terhadap sekumpulan variabel yang ada, sehingga terbentuk satu atau lebih faktor.

Tabel 4: Hasil Ekstraksi Faktor

\begin{tabular}{|l|l}
\hline Component & Initial Eigenvalues
\end{tabular}

\begin{tabular}{|c|c|c|c|}
\hline & Total & $\begin{array}{c}\text { \% of } \\
\text { Variance }\end{array}$ & $\begin{array}{c}\text { Cumulativ } \\
\text { e } \%\end{array}$ \\
\hline 1 & 11.112 & 44.449 & 44.449 \\
2 & 2.638 & 10.551 & 55.000 \\
3 & 1.929 & 7.715 & 62.716 \\
4 & 1.088 & 4.351 & 67.066 \\
5 & .856 & 3.426 & 70.492 \\
6 & .775 & 3.099 & 73.591 \\
7 & .686 & 2.745 & 76.336 \\
8 & .607 & 2.427 & 78.762 \\
9 & .531 & 2.122 & 80.885 \\
10 & .499 & 1.995 & 82.879 \\
11 & .460 & 1.842 & 84.721 \\
12 & .429 & 1.716 & 86.437 \\
13 & .399 & 1.595 & 88.032 \\
14 & .371 & 1.484 & 89.516 \\
15 & .355 & 1.419 & 90.935 \\
16 & .311 & 1.243 & 92.178 \\
17 & .288 & 1.152 & 93.329 \\
18 & .282 & 1.126 & 94.456 \\
19 & .250 & 1.000 & 95.456 \\
20 & .228 & .912 & 96.368 \\
21 & .217 & .867 & 97.234 \\
22 & .201 & .803 & 98.038 \\
23 & .183 & .732 & 98.770 \\
24 & .171 & .683 & 99.453 \\
25 & .137 & .547 & 100.000 \\
\hline$S 4 m b r$ \\
\hline
\end{tabular}

Sumber: Hasil olahan peneliti, 2015

Jumlah faktor yang terbentuk dapat dilihat dari nilai eigen yang lebih besar dari satu. Setelah dilakukan ekstraksi, tampak dalam tabel di atas bahwa faktor yang terbentuk sebanyak empat faktor, dengan masing-masing mempunyai nilai eigen berada pada interval 1,088 sampai 11,112. Setelah ditemukan empat faktor yang terbentuk, maka agar dapat mengetahui beban faktor (factor loading) dari masing-masing faktor perlu dilakukan rotasi faktor sehingga dapat diketahui besar korelasi antara suatu variabel dengan faktor-faktor yang terbentuk. Hasil rotasi faktor yang didapatakan pada faktor terbentuk antara lain sbb:

a. Faktor satu. Faktor ini menjelaskan keragaman dari variabel sebesar 24,396\% dengan nilai eigen $=6,099$. Dari empat faktor yang ditemukan, faktor 1 mempunyai nilai varian yang paling besar dari faktor- 
faktor lainnya. Jika dilihat dari faktor loading, maka variabel kemudahan pemesanan $\left(\mathrm{X}_{4}\right)$ merupakan variabel yang mewakili faktor 1 (satu) dengan faktor loading 0,752. Kemudian disusul dengan kemudahan pencarian situs web dengan faktor loading 0,750, kecepatan waktu mengakses (load time) $\left(\mathrm{X}_{2}\right)$ dengan faktor loading 0,743 , Informasi yang akurat $\left(\mathrm{X}_{6}\right)$ dengan faktor loading 0,739 , Pengalaman secara keseluruhan $\left(\mathrm{X}_{16}\right)$ dengan faktor loading 0,702, Informasi yang lengkap $\left(\mathrm{X}_{5}\right)$ dengan faktor loading 0,675 , Keamanan data pribadi $\left(\mathrm{X}_{17}\right)$ dengan faktor loading 0,656 , Nama domain perusahaan $\left(X_{3}\right)$ dengan faktor loading 0,639, Keamanan sistem pembayaran $\left(\mathrm{X}_{18}\right)$ dengan faktor loading 0,609 , Harga yang kompetitif $\left(\mathrm{X}_{15}\right)$ dengan faktor loading 0,589 , Informasi yang menarik $\left(\mathrm{X}_{7}\right)$ dengan faktor loading 0,572, Ketersediaan dan aksesibilitas $\left(\mathrm{X}_{14}\right)$ dengan faktor loading 0,534, dan Pemaparan informasi yang tepat $\left(\mathrm{X}_{10}\right)$ dengan faktor loading 0,510 .

b. Faktor dua. Mampu menjelaskan keragaman dari variabel sebesar 15,211\% dengan nilai eigen $=3,803$. Jika dilihat dari faktor loading, variabel kecepatan waktu pelayanan $\left(\mathrm{X}_{12}\right)$ merupakan variabel yang mewakili faktor 2 (dua) dengan faktor loading 0,849. Kemudian disusul dengan variabel kemudahan pengaduan keluhan $\left(\mathrm{X}_{11}\right)$ dengan faktor loading 0,821 , ketepatan waktu pelayanan $\left(\mathrm{X}_{13}\right)$ dengan faktor loading 0,819 , tampilan warna website $\left(\mathrm{X}_{8}\right)$ dengan faktor loading 0,599 dan tampilan jenis huruf pada website $\left(\mathrm{X}_{9}\right)$ dengan faktor loading 0,517 .

c. Faktor tiga. Keragaman dari variabel pada faktor ini sebesar $14,681 \%$, dengan nilai eigen $=3,670$, variabel nama baik perusahaan $\left(\mathrm{X}_{22}\right)$ merupakan variabel yang mewakili faktor 3 dengan faktor loading 0,826. Kemudian disusul dengan variabel dikenal luas $\left(\mathrm{X}_{24}\right)$ dengan faktor loading 0,765 , dan reputasi dibanding pesaing $\left(\mathrm{X}_{23}\right)$ dengan faktor loading 0,721 .

d. Faktor empat. Menjelaskan keragaman dari variabel sebesar $12,779 \%$ dan memiliki nilai eigen $=3,195$, variabel personal image $\left(\mathrm{X}_{21}\right)$ merupakan variabel yang mewakili faktor 4 dengan faktor loading 0,751. Kemudian disusul dengan variabel situasi konsumen $\left(\mathrm{X}_{20}\right)$ dengan faktor loading 0,738 , dan kemudahan diingat $\left(\mathrm{X}_{25}\right)$ dengan faktor loading 0,601.

Family members merupakkan satusatunya variabel yang dikeluarkan dari analisis karena nilai loading faktor yang diperoleh 0 , 461, ini berarti nilainya lebih kecil dari 0,5. Pada ke-empat faktor terbentuk diatas penamaan faktor dilakukan dengan cara melihat nilai loading factor yang paling tinggi, dan variabel dari faktor apa saja yang paling mendominasi sehingga dapat diberikan penamaan yang tidak jauh berbeda dengan delapan faktor awal yang telah ditentukan. Faktor satu dengan penamaan faktor "kemudahan dan sistem informasi website", faktor terbentuk yang kedua dengan penamaan faktor "pelayanan konsumen (customer service), faktor ketiga dengan penamaan "citra perusahaan" dan faktor keempat dengan sebutan "motivasi pembelian".

\section{PEMBAHASAN}

Faktor-Faktor yang Mendorong Wisatawan Melakukan Keputusan Pembelian Tiket Pesawat melalui Mobile Booking pada Situs Traveloka.Com

Hasil dari analisis data yang didapatkan menunjukkan bahwa dari delapan faktor awal dengan total 25 variabel tersebut diatas, maka diperoleh empat faktor terbentuk yang mendorong wisatawan melakukan keputusan pembelian tiket pesawat melalui mobile booking pada situs Traveloka.com yaitu:

Faktor 1 (kemudahan dan sistem informasi website) terdiri dari: kemudahan pemesanan $\left(\mathrm{X}_{4}\right)$, kemudahan pencarian situs web $\left(\mathrm{X}_{1}\right)$, kecepatan waktu mengakses $\left(\mathrm{X}_{2}\right)$, informasi yang akurat $\left(\mathrm{X}_{6}\right)$, pengalaman secara keseluruhan $\left(\mathrm{X}_{16}\right)$, informasi yang lengkap $\left(\mathrm{X}_{5}\right)$, keamanan data pribadi $\left(\mathrm{X}_{17}\right)$, nama domain perusahaan $\left(\mathrm{X}_{3}\right)$, keamanan sistem pembayaran $\left(\mathrm{X}_{18}\right)$, harga yang kompetitif $\left(\mathrm{X}_{15}\right)$, informasi yang menarik $\left(\mathrm{X}_{7}\right)$, ketersediaan dan aksesibilitas $\left(\mathrm{X}_{14}\right)$ dan Pemaparan informasi yang tepat $\left(\mathrm{X}_{10}\right)$

Faktor 2 (pelayanan konsumen/customer service) terdiri dari: kecepatan waktu pelayanan $\left(\mathrm{X}_{12}\right)$, kemudahan pengaduan keluhan $\left(\mathrm{X}_{11}\right)$, ketepatan waktu pelayanan $\left(\mathrm{X}_{13}\right)$, tampilan warna website $\left(\mathrm{X}_{8}\right)$, tampilan jenis huruf pada website $\left(\mathrm{X}_{9}\right)$. 
Faktor 3 (citra perusahaan) terdiri dari: nama baik perusahaan $\left(\mathrm{X}_{22}\right)$, dikenal luas $\left(\mathrm{X}_{24}\right)$, dan reputasi dibanding pesaing $\left(\mathrm{X}_{23}\right)$.

Faktor 4 (motivasi pembelian) terdiri dari: personal image $\left(\mathrm{X}_{21}\right)$, situasi konsumen $\left(\mathrm{X}_{20}\right)$, dan kemudahan diingat $\left(\mathrm{X}_{25}\right)$.

\section{Faktor yang Paling Berkontribusi Mendorong Wisatawan Melakukan Keputusan Pembelian Tiket Pesawat Melalui Mobile Booking pada Situs Traveloka.com}

Faktor-faktor yang mendorong

wisatawan melakukan keputusan pembelian tiket pesawat melalui mobile booking pada situs Traveloka.com mendapatkan hasil analisis data sebagai berikut: terdapat 4 (empat) faktor yang terbentuk dari 25 varibel awal yang telah ditetapkan. Faktor yang terbentuk adalah kemudahan dan sistem informasi $(24,396 \%)$, pelayanan konsumen $(15,211 \%)$, citra perusahaan $(14,681 \%)$, dan Motivasi pembelian (12,779\%). Adapun faktor yang paling berkontribusi mendorong wisatawan melakukan keputusan pembelian tiket pesawat melalui mobile booking pada situs Traveloka.com adalah faktor terbentuk yang memiliki faktor laoding tertinggi dari keseluruhan faktor yang terbentuk. Berdasarkan hasil penelitian maka yang menjadi faktor yang paling berkontribusi adalah Faktor Kemudahan dan Sistem Informasi Website, faktor ini terdiri dari 13 variabel yakni: (1) Kemudahan pencarian situs web, (2) kecepatan waktu mengakses (load time), (3) nama domain perusahaan, (4) kemudahan pemesanan, (5) informasi yang lengkap, (6) Informasi yang akurat, (7) informasi yang menarik, (8) Pemaparan informasi yang tepat, (9) ketersediaan dan aksesibilitas, (10) harga yang kompetitif, (11) pengalaman secara keseluruhan, (12) keamanan data pribadi, dan (13) keamanan sistem pembayaran. Hal ini berarti bahwa wisatawan merasa memiliki keinginan atau terdorong untuk melalukan keputusan pembelian tiket pesawat melalui mobile booking pada situs Traveloka.com disebabkan karena kemudahan dalam mencari ataupun mengakses situs Traveloka.com. Kemudahan disini juga berarti kemudahan yang dirasakan wisatawan mulai dari proses pencarian informasi, pemesanan tiket pesawat, melakukan pembayaran sampai dengan mendapatkan tiket pesawat. Hasil diperoleh dikuatkan dengan gaya hidup masyarakat zaman sekarang yang mementingakan proses yang lebih mudah dan cepat. Selain itu menurut Yohanes Suhari, (2008). Faktorfaktor yang mempengaruhi seseorang melakukan transaksi secara online adalah efisiensi pencarian (waktu cepat, mudah dalam penggunaan, dan usaha pencarian mudah), (2) value (harga bersaing dan kualitas baik), dan (3) interaksi (informasi, keamanan, load time, dan navigasi). Abdul Rahim, dkk (2008), juga menjelaskan bahwa konsumen pada saat memesan kamar hotel secara online membutuhkan transaksi yang cepat dan efisien. Berdasarkan hasil dari kedua penelitian diatas serta data yang dihasilkan maka dapat disimpulkan bahwa faktor-faktor yang mendorong seseorang wisatawan melakukan keputusan pembelian tiket pesawat atau pemesanan kamar hotel secara online didasari atas faktor kemudahan pembelian.

\section{SIMPULAN DAN SARAN}

\section{Simpulan}

Berdasarkan hasil analisis yang dilakukan terkait faktor-faktor yang mendorong wisatawan melakukan keputusan pembelian tiket pesawat melalui mobile booking pada situs Traveloka.com maka dapat diambil kesimpulan sebagai berikut:

1. Faktor-faktor yang mendorong wisatawan melakukan keputusan pembelian tiket pesawat melalui mobile booking pada situs Traveloka.com terdir dari 4 (empat) faktor yaitu:
a. Faktor Kemudahan dan Sistem Informasi Website,
b. Faktor Pelayanan konsumen
c. Faktor Citra Perusahaan
d. Faktor Motivasi pembelian

2. Faktor yang paling berkontribusi mendorong wisatawan melakukan keputusan pembelian tiket pesawat melalui mobile booking pada situs Traveloka.com adalah faktor pertama yakni faktor kemudahan dan sistem informasi website, dengan total nilai eigen $=6,099$.

\section{Saran}

1. Saran yang dapat diberikan kepada perusahaan PT. Traveloka Indonesia adalah agar tetap menjaga dan mempertahankan kepercayaan yang diberikan oleh para wisatawan yang telah memilih situs 
Traveloka.com. Selain itu hasil dalam penelitian ini juga dapat dijadikan sebagai masukan untuk menetukan strategi pemasaran kedepanya.

2. Bagi peneliti selanjutnya, diharapakan dapat mengetahui apakah dari keempat faktor yang telah ditemukan oleh peneliti, benar-benar memiliki pengaruh besar dalam mendorong wisatawan melakukan keputusan pembelian tiket pesawat melalui mobile booking.

\section{DAFTAR PUSTAKA}

Abu Bakar, A. R dan Hashim. Fariza. 2008.

The Determinants of Online Hotel Reservations Among University Staffs. Collage of Business Universitas Utara Malaysia, Malaysia. Volume 4, 2008.

Augusty Ferdinand. 2006. Metode Penelitian Manajemen: "Pedoman Penelitian untuk Penulisan Skripsi, Tesis, dan Disertasi Ilmu Manajemen". Semarang : Badan Penerbit Universitas Diponegoro.

Gudono. 2015. "Analisis Data Multivariat".Yogyakarta: BPFE

Hsu Cathy, dkk. 2008. "Tourism Marketing An Asia Pacific Perspective". Singapore: Fabulous Printers Pte Ltd.

Kozak. Metin and Luisa Andreu. 2006. Progress In Tourism Marketing. Amsterdam: Alsevier. P55-65

Suharni, Yohanes. 2013. Keputusan Membeli Secara Online dan Faktor - Faktor yang Mempengaruhinya. Fakultas Informasi Universitas Stikubank Semarang. ISSN: 0854-9524. 